\title{
Barriers and facilitators associated with HIV testing uptake in South African health facilities offering HIV Counselling and Testing
}

\author{
Neo Mohlabane ${ }^{a}$, Bomkazi Tutshana ${ }^{a}$, Karl Peltzer ${ }^{a, b, c, *,}$ \\ Aziza Mwisongo ${ }^{d}$ \\ ${ }^{a}$ HIV, AIDS, TB, and STIs (HAST), Human Sciences Research Council (HSRC), Pretoria, Durban, South Africa \\ ${ }^{\mathrm{b}}$ Department of Psychology, University of Limpopo, Turfloop, South Africa \\ c ASEAN Institute for Health Development, Madidol University, Salaya, Phutthamonthon, Nakhonpathom, 73170, \\ Thailand \\ d School of Public Health, Faculty of Health Sciences, University of Witwatersrand, Johannesburg, South Africa
}

\section{A R T I C L E I N F O}

Article history:

Received 10 February 2015

Accepted 2 November 2015

Available online 7 March 2016

Keywords:

Barriers

Health facilities

HCT testing

Routine HIV testing

South Africa

\begin{abstract}
A B S T R A C T
Background: The scale-up of HIV Counselling and Testing (HCT) in South Africa to 4500 public health facilities and the service's provision in mobile and non-medical sites was aimed at increasing HCT uptake. However, some people still have never had an HIV test. Objective: An HCT survey was carried out to ascertain barriers and facilitators for HIV testing in South Africa.

Methods: A cross-sectional survey of 67 HCT-offering health facilities in 8 South African provinces was undertaken. Individuals $(n=489)$ who had not tested for HIV on the day of the site visit were interviewed on awareness of HCT services, HIV testing history and barriers to HIV testing. Frequencies were run to describe the sample characteristics, barriers and facilitators to HIV testing. Bivariate and multivariate logistic regression was used to identify the association between never tested for HIV with socio-demographics, awareness of HCT services and type of HCT facilities.

Results: In all $18.1 \%$ participants never had an HIV test. Major barriers to HCT uptake comprise being scared of finding out one's HIV test result or what people may say, shyness or embarrassment, avoidance of divulging personal information to health workers and fear of death. In multivariate analysis the age group 55 years and older, and not being recommended to have an HIV test were associated with never had an HIV test. Potential facilitators for HIV testing include community or household HIV testing, providing incentives for those who test for HIV, mandatory HIV testing and disclosure of HIV status by those who test HIV positive.

Conclusion: The benefits of HCT which include the reduction of HIV transmission, the availability of HIV care and treatment needs to be emphasized to enhance HCT uptake.
\end{abstract}

\footnotetext{
* Corresponding author. ASEAN Institute for Health Development, Madidol University, Salaya, Phutthamonthon, Nakhonpathom, 73170, Thailand.

E-mail address: kpeltzer@hsrc.ac.za (K. Peltzer).

Peer review under responsibility of Johannesburg University. 
Health workers also need to recommend HCT to all individuals attending health facilities offering this service.

(C) 2015 The Authors. Publishing services by Elsevier B.V. on behalf of Johannesburg University. This is an open access article under the CC BY-NC-ND license (http:// creativecommons.org/licenses/by-nc-nd/4.0/).

\section{Introduction}

HIV Counselling and Testing (HCT) facilitates early diagnosis for HIV positive persons which helps reduce the risk of further transmission, provides access to care and treatment, while motivating people who test HIV negative to maintain their negative status (Day et al. 2003:665; Peltzer, Matseke, Mzolo, \& Majaja, 2009:2; Subramanian, Gupte, Mathai, Boopathi, \& Dorairaj, 2008:26). This suggests that HCT is vital for both knowledge of one's HIV status and HIV prevention. However, there are still people who have no knowledge of their HIV status. For instance, in sub-Saharan Africa, the region hardest hit by the epidemic, the median of people who knew their HIV status was reported to be below 40\% in 2007-2009 (World Health Organization [WHO], The Joint United Nations Programme on HIV/AIDS [UNAIDS], United Nations International Children's Education Fund [UNICEF] 2010). In South Africa specifically, the percentage of people who reported to have ever had an HIV test and hence are aware of their HIV status was 65.5\% in 2012 (Shisana et al. 2014), 50.8\% in 2008, from $21.4 \%$ in 2002 and $30.5 \%$ in 2005 (Shisana et al. 2008:49). These findings are similar to a study assessing HIV testing attitudes in a black township in Cape Town, 2003 which found that about $53 \%$ of the study participants had never been tested for HIV (Kalichman \& Simbayi, 2003:444). Although there has been an increase in the uptake of HIV testing, a significant number have not been tested yet.

Traditionally, low HIV testing rates were associated with the reliance on Voluntary Counselling and Testing (VCT) which is initiated by the client, as the sole approach to HIV testing (Jürgens, 2006:9). In 2006 the World Health Organization and The Joint United Nations Program on HIV/AIDS developed a draft guidance on Provider-Initiated HIV Testing and Counseling (PITC) to increase the opportunities for HIV diagnosis, thereby reducing the barriers associated with HIV testing (Leon, Naidoo, Mathews, Lewin, \& Lombard, 2010:2; WHO, UNAIDS 2007:14). The PITC approach recommends routine HIV testing and counselling to clients who attend health services regardless of their presenting illness (WHO, UNAIDS 2007:15). It is against this backdrop that in its $\mathrm{Na}$ tional Strategic Plan for HIV \& AIDS and STIs, 2007-2011, the South African government made the fight against HIV/AIDS one of its top priorities by setting up two primary goals: the reduction of new infections by $50 \%$ and the reduction of the impact of HIV and AIDS by expanding access to comprehensive treatment, care and support to $80 \%$ for infected individuals by 2011 (National Department of Health South Africa [DoHSA] 2007:10). To achieve these goals, HCT services offering PITC were scaled up to more than 4500 public health facilities as well as mobile services and non-medical sites
(NDOH, 2007:8). This was followed by the launch of a national HCT campaign in 2010 which targeted 15 million South Africans to test for HIV by June 2011 (UNAIDS 2010:65).

A number of studies conducted in health clinics and hospitals between 2006 and 2010 worldwide have investigated the impact and acceptability HIV testing and counselling in relation to the routine offer of HIV testing (Bassett, Giddy, Nkera, \& Wang, 2007:2; Bokhour, Solomon, Knapp, Asch, \& Gifford, 2009:1109; Creek et al. 2007:103; Jürgens, 2006:6; Leon et al. 2010:2; Nakanjako et al. 2007:754; Wanyenze et al. 2008:303). Overall, routine HIV testing was perceived to be acceptable and helped to increase testing rates, thus enabling awareness of HIV status for patients who had never tested. For instance, in a Ugandan study in two hospitals, of the $98 \%$ participants who accepted testing, a $28 \%$ HIV prevalence was found in patients who had never had an HIV test previously (Wanyenze et al. 2008:304). These findings were consistent with another Ugandan study where 95\% participants accepted testing and about half had an HIV diagnosis (Nakanjako et al. 2007: 756). In terms of HIV diagnosis of previously undiagnosed patients, these findings were consistent with two South African studies, one of which identified an HIV prevalence of $40 \%$ overall while the other study had a $32.7 \%$ HIV prevalence of which $64.9 \%$ had never had an HIV test before (Bassett et al. 2007:5; Leon et al. 2010:5). In terms of the increase in testing rates, however, both studies had lower HIV testing acceptance rates compared to the two Ugandan studies, one had a $76 \%$ testing rate which was lower than their targeted rate and the second study only achieved a $48.6 \%$ HIV testing rate of the eligible participants (Bassett et al. 2007:4; Leon et al. 2010:5). It is evident from these studies that although HIV testing uptake has improved over the years, barriers to testing may still exist.

Previous studies have reported various factors associated with the lack of HIV testing including (1) personal factors, (2) health system factors, and (3) sociodemographic factors. Personal barriers to HIV testing may include lack of knowledge of testing sites (Choi, Lui, Guo, Han, \& Mandel, 2006:40), low perceived risk of infection (Deblonde et al. 2010:423; MacKellar et al. 2011:422; Peralta, Deeds, Hipszer, \& Ghalib, 2007:403), fear of testing HIV positive, discrimination, stigma and rejection (Daftary, Padayatchi, \& Padilla, 2007:574; De Wit \& Adam, 2008:21; MacKellar et al. 2011:421; Musheke et al. 2013:11; Spielberg et al. 2003:322). The fear of discordance has also been a deterrent to HIV testing as a potential indicator of infidelity, thus providing a strain in relationships, particularly marriage (Angotti et al. 2009:2266; Larsson et al. 2010:6; Larsson et al. 2012:73). Other studies reported that men are decision-makers with regards to HIV testing and women have to obtain permission before seeking HIV testing from their spouses (Daftary et al., 2007:574; Råssjö, Darj, Konde-Lule, \& Olsson, 2007:219; Theuring et al. 2009: 96). Furthermore, 
Izugbara, Undie, Mudege, and Ezeh (2009) and Skovdal et al. (2011) report that men refused to test because it was regarded as a sign of vulnerability. Health system barriers may include inconvenient testing hours, location of the HCT site, the cost of testing (Morin et al. 2006:221), concerns about loss of confidentiality (Choi et al. 2006:40), never having been offered an HIV test (Peralta et al. 2007, 403), lack of confidence in the competence of health personnel (Meiberg, Bos, Onya, \& Schaalma, 2008:8), poor staff attitudes (Larsson et al. 2010:6), and unreliability of test results and distrust of testing technologies (Råssjö et al. 2007:218). Socio-demographic factors may include gender (Hutchinson \& Mahlalela, 2006:449; Venkatesh et al. 2011:4), age (Hutchinson \& Mahlalela, 2006; Morin et al. 2006:221; Peltzer et al. 2009:3), cohabiting or marital status (Peltzer et al. 2009:3; Wringe et al. 2008:321), and education level (Gage \& Ali, 2005:156; Haile, Chamber, \& Garrison, 2007:196; Hutchinson \& Mahlalela, 2006:449; Kalichman \& Simbayi, 2003:443; 24, Venkatesh et al. 2011:4; Wringe et al. 2008:323). However, a considerable proportion of these studies tended to focus on HIV testing among specific groups, for instance in sub-Saharan Africa, most studies focused on pregnant women (Obermeyer \& Osborn, 2007:1770).

\section{Problem statement}

A recent nationwide HIV behavioural survey revealed that there is an increase in the uptake of HIV testing services however only about two-thirds (65.5\%) of the population had ever tested for HIV in 2012 (Shisana et al. 2014). This clearly highlights that there are barriers that hinder the uptake of HIV testing services in South Africa. Furthermore, there is limited literature on barriers to testing among HCT non-users.

\section{Purpose of the study}

This study aims to ascertain the most recent barriers to HIV testing among HCT non-users attending health facilities that offer HIV Counselling and Testing.

\section{Definition of key concepts}

The following key concepts have been defined according to the National Department of Health policy guidelines (2010).

\subsection{Client-Initiated Counselling and Testing (also called Voluntary Counselling and Testing)}

HIV Counselling and Testing that involves individuals and couples actively seeking out these services (NDOH 2010:18).

\subsection{HIV Counselling}

An intervention which gives the client an opportunity to be educated and supported in order to explore his or her HIV risk; to learn about his or her HIV status and manage the consequences; to learn about HIV prevention and HIV and AIDS treatment, care and support services; and to learn how to modify their behaviour to reduce the risk of HIV infection.

\subsection{HIV Counselling and Testing (HCT)}

An umbrella term used to describe services that combine both HIV Counselling and Testing. The policy distinguishes between two types of counselling and testing services - those that are client-initiated and those that are provider-initiated. The process is voluntary, and the "three Cs" - informed Consent, Counselling and Confidentiality - must be observed.

\subsection{Provider}

Any person or organization that provides a service, either directly or indirectly, that includes counselling and testing for HIV, with the person tested being told their HIV test result.

\subsection{Provider-Initiated Counselling and Testing (PICT) (also called provider-initiated testing and counselling (PITC)} or routine counselling and testing)

HIV testing and counselling which is initiated and recommended by health care providers to all clients attending health care facilities as a standard component of medical care (NDOH 2010:18).

\subsection{Voluntary counselling and testing (VCT) (also called Client-Initiated Counselling and Testing)}

The situation where individuals or couples actively and voluntarily seek HIV Counselling and Testing at a facility that offers these services (National Department of Health 2010).

\section{Significance}

Previous studies in South Africa have not investigated the HCT barriers and facilitators from the perspective of health facility patients HCT non-users. The study of HCT non-users can provide a better understanding of barriers and facilitators of HCT uptake can help to inform the health system and the community to improve HCT uptake.

\section{Research method and design}

\subsection{Study setting}

This analysis is based on data from an assessment of HCT sites that was conducted in eight provinces of South Africa in 2012. The assessment was meant to cover all nine provinces of South Africa, however one province was excluded from participation because permission was not granted. The main aim of the study was to assess provision of HCT services in South Africa with a focus on the challenges and utility of the different HCT models. The study was conducted in both public and private-sector health facilities in order to document the spectrum of approaches to providing HCT services in South Africa. This paper draws on findings from a survey conducted with HCT non-users. 


\section{Sampling}

The study was a cross-sectional survey of clients from 67 government and NGO HCT sites in 8 of 9 South African provinces, who did not use the site for HIV testing services on the day of the interview, and was part of a larger rapid appraisal of HCT services. A two-stage sampling procedure was used to select HCT sites. Firstly one health district was randomly selected in each province and thereafter convenience sampling was used to select 4 public and 3 private HCT sites per health district. Public HCT sites were stratified by locale (urban and rural) whilst private and NGO were selected on the basis of providing services in a specific setting, using a specific model/approach or providing services to a specific target population. An attempt was made to include both males and females, and service nonusers of different ages, from 16 years of age and older.

A semi-structured questionnaire was administered to a sample of 489 clients utilizing the HCT sites, at the end of the site visit, with the purpose of describing the barriers and facilitators to using HCT services from a user perspective. A convenient sampling procedure was employed for the selection of about 9-14 study participants per site.

\section{Data collection procedure}

The target was to administer questionnaires to health service users who did not receive HIV testing services during their HCT visit. HCT non-service users were intercepted as they were leaving the health facility and recruited for participation in the survey. Clients who expressed a willingness to consider participating when they were approached had the purpose of the survey explained to them using a consent script, and those who formally consented to be interviewed were interviewed. The questionnaire was administered in a private area inside or outside the health facility depending on the availability of space. In instances where there was lack of space inside the facility, some interviews were conducted in private in a shaded waiting area outside the facility. The semi-structured questionnaire was administered by a trained interviewer who was fluent in the dominant local languages. The language used in the interview was either Afrikaans, English, Tswana, Northern Sotho, Venda or Zulu. The questionnaire had been translated from English into these major languages of the target population by Research team members that were fluent in the respective languages, thereafter they were backtranslated into English by a different translator and discrepancies were discussed and resolved. The questionnaire was pilot tested for face validity and understanding with 15 clients who were not part of the sample population.

\section{Measures}

A 24-item questionnaire was used to interview participants who had not had an HIV test on the day of the site visit. This was referred to as HCT service non-user exit questionnaire which consisted of both structured and open-ended questions to ensure validity and reliability of the results. The questionnaire covered the following: Participant's demographics such as age, sex and relationship status; Awareness of HCT services which included a question on whether the participant knew that the site they were visiting offered HIV testing; HIV testing history which was used to explore whether the participants had been previously tested. The participants were also asked, "In general, what things do you think may make it hard for people to be tested for HIV?" Responses were not prompted but classified based on a list of 15 possible responses. Finally, participants were asked if they had any suggestions about how to make it easier for people to be tested for HIV.

\section{Data analyses}

All data analysis was conducted using SPSS version 20 software. The dependent (outcome) variable was a binary variable, "Had an HIV test previously" and "Never had an HIV test". Frequencies were used to define the socio-demographics including: sex, age, relationship status, geotype, province, type of organization and HCT type of the study sample and thus to estimate the prevalence of lack of HIV testing. Frequencies were also run to establish the reported barriers to HIV testing. Open-ended questions were content coded in SPSS for ease of analysis of the themes covered. Bivariate and multivariate analysis was conducted to estimate the association between relevant predictor (independent) variables and the outcome (dependent) variable. The independent variable was "Previous HIV testing". The dependent variables included some of the socio-demographic factors (sex, age, relationship status, geotype, type of organization - public or private and HCT type - hospital or primary health clinic) and awareness of HCT services (knowledge of HIV testing services at the site, being offered to have an HIV test and, being recommended to have an HIV test). Two-sided 95\% confidence intervals are reported and the p-value of less or equal to $5 \%$ is used to indicate statistical significance. Finally, automatic recoding was used to ascertain the participants' suggestions of what could make it easier for people to test for HIV.

\section{Ethical considerations}

Ethical approval for conducting the study was obtained from the Human Sciences Research Council's Ethics Committee (Application Number 9/19/08/09). All interviews took place in a private setting after written informed consent was obtained. No names were recorded on the questionnaire, instead a study participant number was allocated for each respondent. Additionally, data were analysed provincially, and by locality and facility type and not by smaller geographic units.

\section{Results}

\subsection{Socio-demographic characteristics of the study sample}

A total of 625 HCT non-users were approached to participate in the study, 489 (78.2\%) agreed and 136 refused (21.8\%). The 
common reasons for refusal included being busy, hungry or tired; unhappiness with the health system; and no reasons. The total study sample of 489 participants had an overall mean age of 36 years (range 16-85 years). The mean age for males was 34 years (range 17-75 years) while 37 years for females (range 16-85 years). From the total sample of 88 (18.1\%) participants who had never had an HIV test, more males (20.2\%) compared to females (16.7\%) had never tested (see Table 1).

\subsection{Barriers to HIV testing}

Fig. 1 shows that fear of finding out one's HIV test result was reported by most (73\%) participants as the biggest barrier to HIV testing, however, only $16 \%$ of those who had never been tested for HIV reported this to be a major barrier. Being scared

Table 1 - Socio-demographic characteristics of the study sample $(n=489)$.

\begin{tabular}{|c|c|c|c|}
\hline \multirow[t]{2}{*}{ Variables } & $\begin{array}{c}\text { Total } \\
\text { sample }\end{array}$ & $\begin{array}{c}\text { Never tested } \\
\text { for HIV }\end{array}$ & $\begin{array}{l}\text { Tested } \\
\text { for HIV }\end{array}$ \\
\hline & $\mathrm{n}(\%)$ & $\mathrm{n}(\%)$ & $\mathrm{n}(\%)$ \\
\hline \multicolumn{4}{|l|}{ Sex } \\
\hline Males & $193(39.5)$ & $39(44.3)$ & $154(38.6)$ \\
\hline Females & $296(60.5)$ & $49(55.7)$ & $245(61.4)$ \\
\hline \multicolumn{4}{|l|}{ Age (years) } \\
\hline $16-24$ & $115(23.6)$ & $21(24.1)$ & $94(23.6)$ \\
\hline $25-34$ & $150(30.8)$ & $23(26.4)$ & $126(31.7)$ \\
\hline $35-44$ & $100(20.5)$ & $10(11.5)$ & $89(22.4)$ \\
\hline $45-54$ & $68(14.0)$ & $11(12.6)$ & $57(14.3)$ \\
\hline $55 \&$ older & $54(11.1)$ & $22(25.3)$ & $32(8)$ \\
\hline \multicolumn{4}{|c|}{ Currently in a relationship } \\
\hline Yes & $367(75.8)$ & $62(70.5)$ & 303 (76.9) \\
\hline No & $117(24.2)$ & $26(29.5)$ & $91(23.1)$ \\
\hline \multicolumn{4}{|l|}{ Geotype } \\
\hline Urban & $99(20.3)$ & $14(16.1)$ & $85(21.4)$ \\
\hline Peri-urban & $100(20.5)$ & $20(23)$ & 79 (19.8) \\
\hline Informal settlements & $10(2.1)$ & $1(1.1)$ & $9(2.3)$ \\
\hline Rural areas & $278(57.1)$ & $52(59.8)$ & $225(56.5)$ \\
\hline \multicolumn{4}{|l|}{ Province } \\
\hline Western Cape & $43(8.8)$ & $6(6.8)$ & $32(9.3)$ \\
\hline Eastern Cape & $78(16.0)$ & $16(18.2)$ & $62(15.5)$ \\
\hline Northern Cape & $64(13.1)$ & $11(12.5)$ & $53(13.3)$ \\
\hline Free State & $50(10.2)$ & $8(9.1)$ & $42(10.5)$ \\
\hline Kwa-Zulu Natal & $47(9.6)$ & $3(3.4)$ & $43(10.8)$ \\
\hline Gauteng & $51(10.4)$ & $8(9.1)$ & $43(10.8)$ \\
\hline Mpumalanga & $91(18.6)$ & $13(14.8)$ & 77 (19.3) \\
\hline Limpopo & $65(13.3)$ & $23(26.1)$ & $42(10.5)$ \\
\hline \multicolumn{4}{|l|}{ Type of organization } \\
\hline $\begin{array}{l}\text { Government } \\
\text { health service }\end{array}$ & $390(79.8)$ & $75(85.2)$ & $313(78.4)$ \\
\hline NGO & $97(19.8)$ & $13(14.8)$ & $84(21.1)$ \\
\hline Workplace & $1(0.2)$ & - & $1(0.3)$ \\
\hline Private health service & $1(0.2)$ & - & $1(0.3)$ \\
\hline \multicolumn{4}{|l|}{ HCT type } \\
\hline Hospital & $113(23.2)$ & $18(20.7)$ & $95(23.8)$ \\
\hline $\begin{array}{l}\text { Primary health } \\
\text { care clinic }\end{array}$ & $277(56.8)$ & $57(65.5)$ & $218(54.6)$ \\
\hline Stand-alone & $10(10.5)$ & $8(9.2)$ & $43(10.8)$ \\
\hline Mobile HCT service & $10(2.00)$ & - & $10(2.5)$ \\
\hline Outreach & 19 (3.9) & $4(4.6)$ & $15(3.8)$ \\
\hline Community Center & $17(3.5)$ & - & $17(4.3)$ \\
\hline Workplace & $1(0.2)$ & - & $1(0.3)$ \\
\hline
\end{tabular}

of what people may say was cited as the second biggest barrier (49\%; $15 \%$ for non-testers) to HIV testing, followed by shyness or embarrassment (28\%; $20 \%$ for non-testers) and avoidance of divulging personal information to health workers $(24 \% ; 19 \%$ for non-testers). Staff attitudes (3\%; 19\% for non-testers), lack of knowledge of testing sites $(3 \% ; 35 \%$ for non-testers) and lack of treatment availability (6\%; $56 \%$ for non-testers) for HIV positive persons were reported among the least barriers to HIV testing. Only $2 \%$ of the participants reported inconvenient site opening hours as a barrier to HIV testing and none $(0 \%)$ of those who had never been tested for HIV reported this to be the case.

The "other" category prompted respondents to mention any other barriers that were not mentioned under the list of barriers to HIV testing provided. Previous HIV testers specified the following factors as barriers to HIV testing: Fear of death (33\%); Being uncertain of lifestyles which includes having too many partners and lack of condom use (20\%); Being afraid of the stigma associated with HIV/AIDS and taking treatment for HIV (11\%); Do not think that they are at risk (9\%); In denial of HIV/AIDS (7\%); Lack of understanding of the virus (6\%); Being scared of what partners may say when one tests HIV positive (4\%); Not being ready to test for HIV (4\%); Travel costs to HCT sites (2\%); Testing time (2\%) and Lack of motivation to test (2\%). For those who had never tested for HIV the "other" barriers were: Fear of death (33\%); Being uncertain of lifestyles (28\%); Not being ready to test (11\%); Being afraid of stigma (11\%); Lack of understanding of HIV (11\%) and Lack of motivation to test for HIV (6\%).

\subsection{Factors associated with never tested for HIV}

In bivariate analyses the age group 55 years and older, awareness of HIV testing services at the respective site(s), not being offered and not being recommended to have an HIV test by staff were all associated with never had an HIV test. In multivariate analyses, only the age group 55 years and older and not being recommended to have an HIV test were associated with never had an HIV test while awareness of HIV testing services in the site and not being offered an HIV test were no longer associated with never tested. Sex, relationship status and geotype were not associated with never tested for HIV (see Table 2).

\subsection{Potential facilitators for HIV testing}

Fig. 2 indicates that HIV/AIDS education was perceived as a major (32\%) facilitator for HIV testing, followed by community or household HIV testing (21\%), providing incentives for those who test for HIV and mandatory HIV testing at $11 \%$ each, disclosure of HIV status by those who test HIV positive and good staff attitudes at $6 \%$ each. Those who had never tested for HIV considered community or household testing and HIV testing incentives as equally $(17 \%)$ important to encourage testing while none of them considered disclosure of HIV status by HIV positive persons as important. Mandatory HIV testing, good staff attitudes (for instance respect and keeping patient information confidential) and integrating HCT to general health care were equally (7\%) considered potential facilitators for HIV testing by those who had never tested for HIV. 


\section{Things that make it difficult for people to be tested fo HIV}

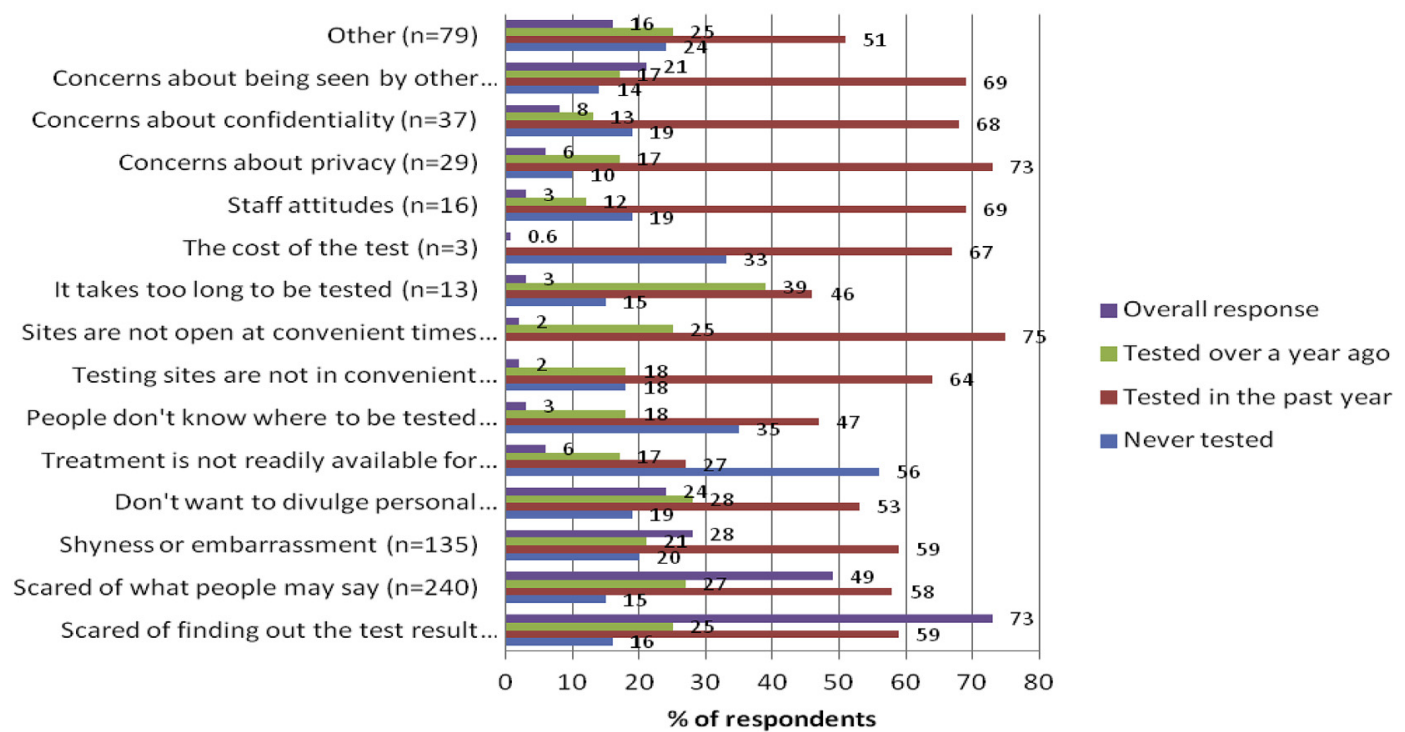

Fig. 1 - Barriers to HIV testing.

Table 2 - Bivariate and multivariate analysis of factors associated with never tested for HIV.

\begin{tabular}{|c|c|c|c|c|c|}
\hline & $\begin{array}{c}\text { Never tested for HIV } \\
\mathrm{N}(\%)\end{array}$ & $\begin{array}{c}\text { Crude OR } \\
\text { OR }(95 \% \text { CI })\end{array}$ & P-value & $\begin{array}{c}\text { Adjusted OR } \\
\text { OR }(95 \% \text { CI })\end{array}$ & P-value \\
\hline \multicolumn{6}{|l|}{ Demographics } \\
\hline Sex & & & 0.321 & & \\
\hline Male & $39(20.2)$ & 1.00 & & & \\
\hline Female & 49 (16.7) & $0.79(0.49-1.25)$ & 0.321 & - & \\
\hline Age & & & 0.000 & & \\
\hline $16-24$ & $21(18.4)$ & 1.00 & & 1.00 & \\
\hline $25-34$ & $23(15.5)$ & $0.77(0.39-1.51)$ & 0.457 & $0.77(0.39-1.51)$ & 0.459 \\
\hline $35-44$ & $10(10.1)$ & $0.46(0.19-1.09)$ & 0.090 & $0.46(0.19-1.09)$ & 0.080 \\
\hline $45-54$ & $11(16.2)$ & $0.79(0.33-0.89)$ & 0.701 & $0.79(0.33-1.89)$ & 0.603 \\
\hline 55 and older & $22(40.7)$ & $3.03(1.41-6.48)$ & 0.002 & $3.03(1.41-6.48)$ & 0.004 \\
\hline Relationship status & & & 0.203 & & \\
\hline Yes & $26(22.2)$ & 1.00 & & & \\
\hline No & $62(17)$ & $1.396(0.83-2.33)$ & 0.203 & - & \\
\hline Geotype & & & 0.715 & & \\
\hline Informal/Rural & $53(18.5)$ & 1.00 & & & \\
\hline Urban/Peri-urban & $34(17.2)$ & $0.91(0.56-1.47)$ & 0.715 & - & \\
\hline \multicolumn{6}{|l|}{ Awareness of HCT services } \\
\hline Awareness of HCT at the site & & & 0.016 & & \\
\hline Yes & $67(16)$ & 1.00 & & 1.00 & \\
\hline No & $19(28.4)$ & $2.07(1.14-3.74)$ & 0.016 & $1.54(0.80-2.95)$ & 0.192 \\
\hline Offered an HIV test during site visit & & & 0.047 & & \\
\hline Yes & $26(13.8)$ & 1.00 & & 1.00 & \\
\hline No & $62(20.9)$ & $1.66(1.00-2.73)$ & 0.047 & $0.86(0.42-1.78)$ & 0.699 \\
\hline Recommended an HIV test site visit & & & 0.003 & & \\
\hline Yes & $16(10.3)$ & 1.00 & & 1.00 & \\
\hline No & 68 (21.6) & $2.39(1.33-4.28)$ & 0.003 & $2.44(1.08-5.52)$ & 0.032 \\
\hline \multicolumn{6}{|l|}{ HCT facilities } \\
\hline Type of organization & & & 0.178 & & \\
\hline Public & 75 (19.3) & 1.00 & & & \\
\hline NGO & $13(13.4)$ & $0.64(0.34-1.22)$ & 0.178 & & \\
\hline HCT Type & & & 0.207 & & \\
\hline Hospital & $18(18.5)$ & 1.00 & & & \\
\hline Primary HC/Clinic & $57(20.7)$ & $1.38(0.77-2.47)$ & 0.278 & & \\
\hline Stand alone & $8(15.7)$ & $0.98(0.39-2.43)$ & 0.969 & & \\
\hline Mobile/Outreach & $4(8.5)$ & $0.49(0.15-1.53)$ & 0.222 & & \\
\hline
\end{tabular}




\section{Potential facilitators for HIV testing}

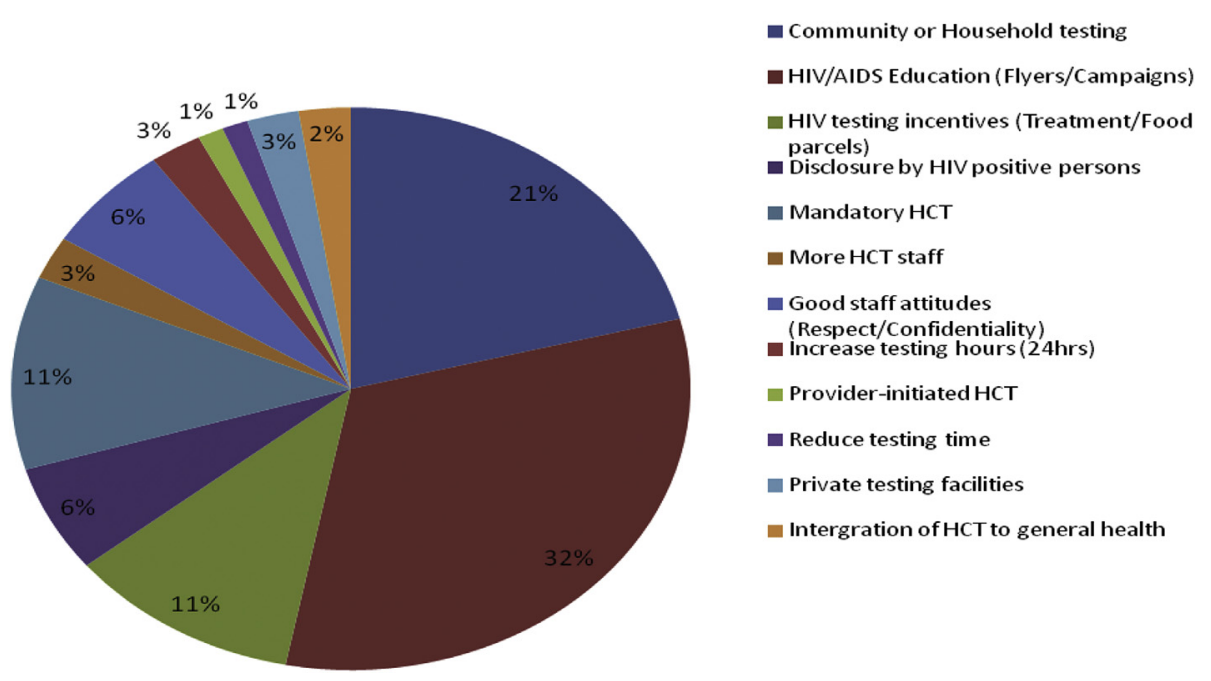

Fig. 2 - Potential facilitators for HIV testing.

\section{Discussion}

The study found that about $18.1 \%$ of people who use health facilities that offer HCT had never tested for HIV. These findings suggest that the South African government has made major strides in ensuring that the majority of the population is tested for HIV (NDOH, 2007:42), compared to previously reported rates of non-HIV testing (Kalichman \& Simbayi, 2003:446; Shisana et al. 2008). Further improvement in the HIV testing uptake of those who have never tested would be beneficial for prevention, care and treatment opportunities (Day et al. 2003:671; Peltzer et al. 2009:7; Subramanian et al. 2008:26).

\subsection{Barriers to HIV testing}

Overall, the major barriers to HIV testing in the current study seem to be more personal than structural. For instance, fear of getting an HIV positive result, being scared of what people may say, shyness or embarrassment and fear of divulging personal information to health workers were all considered as the biggest barriers to HIV testing. These findings are consistent with those found in a systematic review of barriers to HIV testing in Europe (Deblonde et al. 2010:429) where the majority of barriers was perceived to be more personal than health care or institutionally (policy level) related. However, the participants who had never had an HIV test in the current study seemed to report more on structural factors such as not being offered and not being recommended to have an HIV test by staff among the major barriers to HIV testing.

Additional (other) barriers to HIV testing included fear of death and this fear seemed to be related to a lack of understanding of the HIV virus. Having too many partners and not using condoms seemed to be related to uncertainty about HIV status and some participants seemed to be concerned about their partner's reactions if they were to test positive. This is consistent with previous studies that found HIV testing to be avoided by those who were unfaithful as they feared potential discordance with their partners (Musheke et al. 2013:9; Råssjö et al. 2007:220). Stigma also seemed to be a major barrier and a few of the participants reported that non-testers probably fear that when one tests HIV positive, they will eventually have to take treatment which would in turn indicate to others that they are HIV positive. This stigma may potentially be related to the fear of discrimination and rejection, as found in other studies (De Wit \& Adam, 2008:21; Spielberg et al. 2003; Van Dyk \& Van Dyk, 2003:121).

\subsection{Factors associate with never tested for HIV}

In bivariate analyses, this study found that the age group 55 years and older was associated with never had an HIV test. This is consistent with other studies that have found age to be associated with testing or not testing for HIV (Meiberg et al. 2008:8; Morin et al. 2006:222; Peltzer et al. 2009:7). The majority of the participants who had never tested for HIV in this study reported that they knew that people could be tested for $\mathrm{HIV}$ at the respective site. This finding is inconsistent with a study that found the majority of non-testers to be unaware of HIV testing sites (Choi et al. 2006:40). Similar to a study that looked at barriers to HIV testing among adolescents, not being offered an HIV test was also associated with not testing for HIV in the current study.

Additionally, not being recommended to have an HIV test was associated with never had an HIV test in bivariate analysis. Not testing for HIV has always been associated with being male (Choi et al. 2006:40) but in the current study, the difference between male and female non-testers were low 
and therefore not statically significant. The fact that sex (gender) was not associated with never tested for HIV is encouraging as it suggests that, HIV testing among men has started to improve in comparison with previous research (Larsson et al. 2010:7; Meiberg et al. 2008:8). The study found that both the age group 55 and older and not being recommended to have an HIV test increased the odds of not testing.

\subsection{Potential facilitators for HIV testing}

Despite the many HIV/AIDS education campaigns that have been provided in the past, the participants in the current study reported that having campaigns at schools, workplaces and over weekends would facilitate HIV testing. Community or household HIV testing was perceived by some participants as a potential facilitator because they felt that some people, particularly those in the rural areas only go health care centers when there is sickness and thus this type of testing would ensure that these people also get the opportunity to test. This is inconsistent with the one of the findings in this study which found no significant difference in testing between those in rural and urban communities. The incentives that the participants in this study alluded to include, giving treatment after diagnosis to those who test positive and giving food parcels to those who do an HIV test. A number of those who had never tested for HIV felt that these incentives were necessary to encourage testing. This potentially indicates that for these individuals lack of these incentives (particularly treatment) has served as a barrier to HIV testing, as has been found in other studies (Van Dyk \& Van Dyk, 2003:121). As in other studies (Choi et al. 2006:40), good staff attitudes were also considered to potentially encourage testing by those who had never tested previously.

\subsection{Limitations}

This study might not have studied all the factors such as HIV communication (Choi et al. 2006:41; Kalichman \& Simbayi, 2003:446; Larsson et al. 2010:8) influencing HCT at the health facility. Further, social desirability may have influenced some of the responses from study participants. However, participants were requested to provide written informed consent only after they were fully aware of the study details and they were assured of confidentiality hence bias may be unlikely.

\subsection{Recommendations}

Healthcare workers need to recommend HCT to all individuals attending health facilities offering this service as stipulated by the Provider-initiated testing and counselling model. According to the WHO/UNAIDS guidelines (2007), an HIV test is recommended to all patients as a standard part of medical care. Interventions such as targeted HIV awareness campaigns are needed to encourage older people to test for HIV. Confidentiality has been highlighted as a barried to HIV testing in this study hence measures should be put in place in order to improve confidentiality of the HCT service. Additionally, alternative models of HCT such as home and community based models should be considered in order to improve the uptake of HIV testing particularly in those settings where conventional models are unsuccessful. Lastly, individuals testing HIV positive should be linked to support, care and treatment services soon after diagnosis as a measure of incentivizing HIV testing.

\section{Conclusion}

A significant number of health facility patients had never tested for HIV. Several barriers and facilitators of HCT have been identified, which can guide interventions to improve HCT uptake. The lack of association between sex and never tested for HIV as well as between geotype and never tested for HIV suggests that there is potentially equitable access to HIV care and treatment, however, further research is needed to ascertain the validity of this statement. The benefits of HIV Counselling and Testing, which comprise the reduction of further HIV transmission, access to care and treatment needs to be emphasized to encourage more people to test for HIV. Patients also need to be made to understand that an HIV positive status is not synonymous to a death sentence, particularly with the increasing availability of HIV treatment.

\section{Authors' contributions}

BT, KP, AM and NM conceptualized, analysed and interpreted the data, drafted and revised the manuscript. All authors read and approved the final draft of the manuscript.

\section{Acknowledgements}

This research has been supported by the President's Emergency Plan for AIDS Relief (PEPFAR) through the Centers for Disease Control and Prevention (CDC) under the terms of Cooperative Agreement Number U2G/PS000570. Gladys Matseke's contribution in the data collection process is hereby acknowledged.

\section{R E F E R E N C E S}

Angotti, N., Bula, A., Gaydosh, L., Kimchi, E. Z., Thornton, R. L., \& Yeatman, S. E. (2009). Increasing the acceptability of HIV Counselling and Testing with three C's: convenience, confidentiality and credibility. Social Science \& Medicine, 68(12), 2263-2270. http://dx.doi.org/10.1016/j.socscimed.2009.02.041.

Bassett, I. V., Giddy, J., Nkera, J., \& Wang, B. (2007). Routine voluntary HIV testing in Durban, South Africa. The experience from an outpatient department. Journal of the Acquired Immune Deficiency Syndrome, 46(2), 181-186. http://dx.doi.org/10.1097/ QAI.0b013e31814277c8.

Bokhour, B. G., Solomon, J. L., Knapp, H., Asch, S. M., \& Gifford, A. L. (2009). Barriers and facilitators to routine HIV testing in VA primary care. Journal of General and Internal Medicine, 24(10), 1109-1114. http://dx.doi.org/10.1007/s11606009-1078-6.

Choi, K. H., Lui, H., Guo, Y., Han, L., \& Mandel, J. S. (2006). Lack of HIV testing and awareness of HIV infection among men who have sex with men, Beijing, China. AIDS Education and 
Prevention, 18, 33-43. http://dx.doi.org/10.1521/ aeap.2006.18.1.33.

Creek, T. L., Ntumy, R., Seipone, K., Smith, M., Mogodi, M., Smit, M., et al. (2007). Successful introduction of routine optout HIV testing in antenatal care in Botswana. Journal of the Acquired Immune Deficiency Syndrome, 45, 102-107. http:// dx.doi.org/10.1097/QAI.0b013e318047df88.

Daftary, A., Padayatchi, N., \& Padilla, M. (2007). HIV testing and disclosure: a qualitative analysis of TB patients in South Africa. AIDS Care, 19(4), 572-577. http://dx.doi.org/10.1080/ 09540120701203931.

Day, J. H., Miyamura, K., Grant, A. D., Leeuw, A., Munsamy, J., Baggaley, R., et al. (2003). Attitudes to HIV voluntary counselling and testing among mineworkers in South Africa: will availability of antiretroviral therapy encourage testing? AIDS Care, 15, 665-672. http://dx.doi.org/10.1080/ 0954012030001595140.

De Wit, J. B. F., \& Adam, P. C. G. (2008). To test or not to test: psychosocial barriers to HIV testing in high-income countries. HIV Medicine, 9(2), 20-22. http://dx.doi.org/10.1111/j.14681293.2008.00586.x.

Deblonde, J., De Koker, P., Hamers, F. F., Fontaine, J., Luchters, S., \& Temmerman, M. (2010). Barriers to HIV testing in Europe: a systematic review. European Journal of Public Health, 20(4), 422-432. http://dx.doi.org/10.1093/eurpub/ckp231.

Gage, A. J., \& Ali, D. (2005). Factors associated with self-reported HIV testing among men in Uganda. AIDS Care, 17(2), 153-165. http://dx.doi.org/10.1080/09540120512331325635.

Haile, B. J., Chamber, J. W., \& Garrison, J. L. (2007). Correlates of HIV knowledge and testing: results of a 2003 South African HIV Survey. Journal of Black Studies, 38, 194-208.

Hutchinson, P. L., \& Mahlalela, X. (2006). Utilization of voluntary counseling and testing services in the Eastern Cape, South Africa. AIDS Care, 18(5), 446-455. http://dx.doi.org/10.1080/ 09540120500213511.

Izugbara, C. O., Undie, C. C., Mudege, N. N., \& Ezeh, A. C. (2009). Male youth and voluntary counselling and HIV-testing: the case of Malawi and Uganda. Sex Education, 9(3), 243-259. http:// dx.doi.org/10.1080/14681810903059078.

Jürgens, R. (2006). "Routinizing" HIV testing in low- and middleincome countries background paper. New York: Public Health Program of the Open Society Institute.

Kalichman, S. C., \& Simbayi, L. C. (2003). HIV testing attitudes, AIDS stigma, and voluntary HIV Counselling and Testing in a black township in Cape Town, South Africa. Sexually Transmitted Infections, 79(6), 442-447. http://dx.doi.org/10.1136/ sti.79.6.442.

Larsson, E. C., Thorson, A., Nsabagasani, X., Namusoko, S., Popenoe, R., \& Ekström, A. M. (2010). Mistrust in marriageReasons why men do not accept couple HIV testing during antenatal care-a qualitative study in eastern Uganda. BioMedCentral Public Health, 10, 769. http://dx.doi.org/10.1186/ 1471-2458-10-769.

Larsson, E. C., Thorson, A., Pariyo, G., Conrad, P., Arinaitwe, M., Kemigisa, M., et al. (2012). Opt-out HIV testing during antenatal care: experiences of pregnant women in rural Uganda. Health Policy and Planning, 27(1), 69-75. http:// dx.doi.org/10.1093/heapol/czr009.

Leon, N., Naidoo, P., Mathews, C., Lewin, S., \& Lombard, C. (2010). The impact of provider-initiated (opt-out) HIV testing and counseling of patients with sexually transmitted infection in Cape Town, South Africa: a controlled trial. Implementation Science, 5, 8. http://dx.doi.org/10.1186/17485908-5-8.

MacKellar, D. A., Whalen, C. C., Samuelsen, K., Sanchez, T., Smith, A., Denson, D., et al. (2011). Reasons for not HIV testing, testing intentions, and potential use of an over-the-counter rapid HIV test in an internet sample of men who have sex with men who have never tested for HIV. Sexually Transmitted Diseases, 38(5), 419-428. http://dx.doi.org/10.1097/ OLQ.0b013e31820369dd.

Meiberg, A. E., Bos, A. E. R., Onya, H. E., \& Schaalma, H. P. (2008). Fear of stigmatization as barrier to voluntary HIV Counselling and Testing in South Africa. East African Journal of Public Health, 5(2), 49-54.

Morin, S. F., Khumalo-Sakutukwa, G., Charlebois, E. D., Routh, J., Fritz, K., Lane, T., et al. (2006). Removing barriers to knowing HIV status same-day mobile HIV testing in Zimbabwe. Journal of the Acquired Immune Deficiency Syndrome, 41, 218-224. http:// dx.doi.org/10.1097/01.qai.0000179455.01068.ab.

Musheke, M., Ntalasha, H., Gari, S., Mckenzie, O., Bond, V., Martin-Hilber, A., et al. (2013). A systematic review of qualitative findings on factors enabling and deterring uptake of HIV testing in Sub-Saharan Africa. BioMedCentral Public Health, 13, 220-236. http://dx.doi.org/10.1186/1471-2458-13220.

Nakanjako, D., Kamya, M., Daniel, K., Mayanja-Kizza, H., Whalen, J. F. C., \& Katabira, E. (2007). Acceptance of routine testing for HIV among adult patients at the medical emergency unit at a National Referral Hospital in Kampala, Uganda. AIDS and Behavior, 11, 753-758. http://dx.doi.org/ 10.1007/s10461-006-9180-9.

National Department of Health SA. (2007). HIV and AIDS and STI National Strategic Plan for South Africa 2007-2011. Pretoria: Department of Health.

National Department of Health SA. (2010). National HIV Counselling and Testing (HCT) policy guidelines 2010. Pretoria: Department of Health.

Obermeyer, C. M., \& Osborn, M. (2007). The utilization of testing and counseling for HIV: a review of the social and behavioral evidence. American Journal of Public Health, 97, 1762-1774. http://dx.doi.org/10.2105/AJPH.2006.096263.

Peltzer, K., Matseke, G., Mzolo, T., \& Majaja, M. (2009). Determinants of knowledge of HIV status in South Africa: results from a population-based HIV survey. BioMedCentral Public Health, 9, 174. http://dx.doi.org/10.1186/1471-2458-9-174.

Peralta, L., Deeds, B. G., Hipszer, S., \& Ghalib, K. (2007). Barriers and facilitators to adolescent HIV testing. Aids Patient Care \& Stds, 21(6), 400-4008. http://dx.doi.org/10.1089/apc.2006.0112.

Råssjö, E. B., Darj, E., Konde-Lule, J., \& Olsson, P. (2007). Responses to VCT for HIV among young people in Kampala, Uganda. African Journal of AIDS Research, 6(3), 215-222. http://dx.doi.org/ 10.2989/16085900709490417.

Shisana, O., Rehle, T., Simbay,i, L. C., Zuma, K., Jooste, S., Zungu, N., et al. (2014). South African national HIV prevalence, incidence and behaviour survey, 2012. Cape Town: HSRC Press.

Shisana, O., Rehle, T., Simbayi, L. C., Zuma, K., Jooste, S., Pillayvan-Wyk, V., et al. (2008). South African national HIV prevalence, incidence, behaviour and communication survey 2008: A turning tide among teenagers? Cape Town: HSRC Press.

Skovdal, M., Campbell, C., Madanhire, C., Mupambireyi, Z., Nyamukapa, C., \& Greyson, S. (2011). Masculinity as a barrier to men's use of HIV services in Zimbabwe. Global Health, 7(1), 13. http://dx.doi.org/10.1186/1744-8603-7-13.

Spielberg, F., Branson, B. M., Goldbaum, G. M., Lockhart, D., Kurth, A., Celum, C. L., et al. (2003). Overcoming barriers to HIV testing: preferences for new strategies among clients of a needle exchange, a sexually transmitted disease clinic, and sex venues for men who have sex with men. Journal of the Acquired Immune Deficiency Syndrome, 32, 318-327.

Subramanian, Y., Gupte, M. D., Mathai, A. K., Boopathi, K., \& Dorairaj, V. S. (2008). Perception of HIV among attendees at an STD clinic in India. AIDS Care, 20(1), 26-34. http://dx.doi.org/ 10.1080/09540120701427480.

Theuring, S., Mbezi, P., Luvanda, H., Jordan-Harder, B., Kunz, A., \& Harms, G. (2009). Male involvement in PMTCT services in 
Mbeya region, Tanzania. AIDS and Behavior, 13(1), 92-102. http://dx.doi.org/10.1007/s10461-009-9543-0.

Van Dyk, A. C., \& Van Dyk, P. J. (2003). "What is the point of knowing?": psychosocial barriers to HIV/AIDS Voluntary Counselling and Testing programmes in South Africa. South African Journal of Psychology, 33(2), 118-125. http://dx.doi.org/ 10.1177/008124630303300207.

Venkatesh, K. K., Madiba, P., De Bruyn, G., Lurie, M. N., Coates, T. J., \& Gray, G. E. (2011). Who gets tested for HIV in a South African urban township? Implications for test and treat and gender-based prevention Interventions. Journal of the Acquired Immune Deficiency Syndrome, 56(2), 151-165. http:// dx.doi.org/10.1097/QAD.0b013e32834b4ced.

Wanyenze, R. K., Nawavvu, C., Namale, A. S., Mayanja, B., Bunnell, R., Abang, B., et al. (2008). Acceptability of routine HIV Counselling and Testing, and HIV seroprevalence in Ugandan hospitals. Bulletin of the World Health Organization, 86, 302-309. http://dx.doi.org/10.1097/QAD.0b013e328321e40b.

World Health Organization, The Joint United Nations Programme on HIV/AIDS. (2007). Guidance on provider-initiated HIV testing and counseling in health facilities. Geneva: World Health Organization. World Health Organization, The Joint United Nations Programme on HIV/AIDS, United Nations International Children's Education Fund. (2010). Towards Universal Scaling Up Priority HIV/AIDS Interventions in the Health Sector: Progress Report 2010. Geneva: World Health Organization.

Wringe, A., Isingo, R., Urassa, M., Maiseli, G., Manyalla, R., Changalucha, J., et al. (2008). Uptake of HIV voluntary counseling and testing services in rural Tanzania: implications for effective HIV prevention and equitable access to treatment. Tropical Medicine and International Health, 13(3), 319-327. http://dx.doi.org/10.1111/j.1365-3156.2008.02005.x. 